\title{
A Direção de Arte no Cinema: uma abordagem sistêmica sobre seu processo de criação
}

Art Direction in the Cinema: a systemic approach about its creation process

Marcelo Moreira Santos ${ }^{i}$

\section{Resumo}

O presente artigo tem como objetivo entender o papel do Diretor de Arte dentro de uma produção cinematográfica de caráter ficcional. Tendo como fundamento analítico os teóricos dos sistemas Edgar Morin e Jorge Vieira, o texto nos conduz a uma reflexão sobre o processo de co-autoria, fugindo das simplificações e trazendo a complexidade à poética do cinema. O artigo ainda aborda os aspectos antogônicos e contraditórios de duas metodologias de produção: a) de um lado o burocratizado modelo hollywoodiano fordista-taylorista adotado como parâmetro organizacional em produções cinematográficas no começo do século XX pelo cinema de indústria; b) de outro o modelo elitizado e romântico do "cinema de autor" cuja matriz relega apenas ao cineasta a assinatura de um filme; para depois complexificá-los por meio de parâmetros sistêmicos de análise. O artigo termina expondo o caminho evolutivo encontrado no processo de criação vinculado ao Diretor de Arte e qual seu papel na consolidação da poética cinemática de um diretor de cinema.

Palavras-Chaves: Direção de Arte, Poética do Cinema, Análise Sistêmica, Autoria Colaborativa.

\section{Abstract}

This article aims to understand the role of the Art Director within a fictional film production. Taking as analytical basis the systemic theorists Edgar Morin and Jorge Vieira, the text leads us to a reflection on the process of co-authorship, avoiding simplifications and bringing complexity to the poetics of cinema. The article also addresses the contradictory and antagonic aspects of two methodologies of production: a) on the one hand, the bureaucratic FordistTaylorist model adopted as an organizational parameter in cinematographic productions in the early twentieth century by the cinema industry; $b$ ) on the other hand, the elitist and romantic model of "author cinema" whose matrix relegates only to the filmmaker the signature of a film; as to complexify them through systemic parameters of analysis. The article ends by exposing the

Revista Digital do LAV - Santa Maria - vol. 10, n. 1, p. 14 - 30 - jan./abril. 2017 ISSN 1983 7348 http://dx.doi.org/10.5902/1983734823914 
evolutionary path found in the creation process linked to the Art Director and what is their role in consolidating the cinematic poetics of a filmmaker.

Keywords: Art Director, Poetics of Cinema, Systemic Analysis, Colaborative Authorship.

O filme é uma criação da coletividade.

Walter Benjamin

\section{Introdução:}

Dentro do campo dos estudos voltados ao cinema, a teoria, a prática e a interpretação fílmica são tratadas como 'áreas' distintas que, muito embora, influem umas sobre as outras, são tomadas como elementos específicos, às vezes isolados e isolantes. Isso fica mais claro ao se observar as grades de ensino de graduações e especializações em que tal fragmentariedade se torna o fundamento de sua estruturação. Assim, dado o rigor metodológico burocrático das academias, muito influenciado pelo perfil hierarquizado e particionado da sociedade industrial, tais aspectos isolacionistas acabam se sobrepondo, e o cinema acaba sendo tratado como algo cheio de divisões, fragmentações e reduções.

Assim, as disciplinas: linguagem cinematográfica, teoria do cinema, direção de arte, direção de fotografia, montagem, direção de atores, roteiro, direção etc., são apresentas como particionadas, isoladas, dentro de escopos específicos. Nesse contexto, as partes são dimensionadas, mas as dialogias, sinergias, intercâmbios com e entre as partes são mudas, cegas e surdas, como se o cinema fosse feito sem essas intersemioses, sem essas associações, cooperações e partilhas, tanto de agentes semióticos quantos dos signos por estes criados, produzidos e integrados às cenas e ao filme.

Tal contradição epistemológica e ontológica não podem permanecer ignoradas, ao contrário, fugindo das simplificações que rondam o debate a respeito da autoria cinematográfica, o que se proprõe aqui, por meio das teorias sistêmicas, é complexificar a autoria do cinema e sua poética. Assim, ao complexificar a sinergia dos agentes semióticos e dos signos que estes produzem, se complexifica o próprio discurso e a maneira de se assistir e interpretar um filme.

\section{Sobre Riscos, Paradigmas e Autorias}

Revista Digital do LAV - Santa Maria - vol. 10, n. 1, p. 14 - 30 - jan./abril. 2017 ISSN 1983 7348 http://dx.doi.org/10.5902/1983734823914 
Existe muita instabilidade e risco na produção de um filme; desde o estágio inicial de produção de um roteiro - da escolha da ideia ao desenvolvimento das cenas e suas sequências -, passando pela pré-produção que implica orçamento, seleção de equipe especializada, elenco, estruturação de filmagem, pesquisa e definições estéticas de abordagem e construção audiovisual; bem como a fase de filmagem propriamente dita com seu cronograma custoso e imprevisível, afeito tanto ao acaso quanto à regularidade, dependendo muitas vezes de fatores extras e múltiplos que podem ser mensurados previamente ou não; chegando à fase de finalização, montagem e pós-produção que implica novas decisões de abordagem das cenas e material filmado, ou ainda inserção de cenários e personagens via tecnologia digital, ou desenvolvimento de roteiro de áudio, mixagem e produção de sons específicos e trilha sonora, recriando, portanto, novos dilemas e algumas vezes redefinindo todo o filme nesta fase final.

Somada a isso, ainda existe a questão da receptividade com o público. No caso do cinema de indústria, esse momento é crucial, pois o retorno do investimento dos estúdios depende dessa aceitação que, sobretudo, significa lucro e poder de reinvestimento em novas produções, gerando um ciclo permanente ou cadeia produtiva, sustentado não apenas por este estágio da produção, mas por um tripé composto ainda pela distribuição e divulgação, movidos exatamente para disseminar o filme e disponibilizá-lo ao maior número de espectadores possíveis. Já no caso do chamado "cinema de arte" e/ou cinema de autor, muitas vezes subsidiados por governos ou instituições e entidades locais, regionais e/ou nacionais, e cujas produções são rotuladas como 'independentes', essa visão de lucro é substituída por uma preocupação em expressar uma identidade sociocultural por meio de uma cinematografia representativa de um contexto, de um país e/ou de uma visão de mundo. Com menos poder de disseminação, tais filmes trilham seu caminho de "sucesso" ou "aceitação" pelas premiações e destaques em diversos festivais em seus países de origem e/ou fora destes. Em muitos casos, por causa da chancela destes festivais, novos diretores e profissionais do meio são descobertos e suas cinematografias e carreiras são impulsionadas e catapultadas na direção de novas produções, iniciando seus ciclos autorais e/ou co-autorais.

De fato, lidar com o cinema é lidar com o instável, com o risco em todas as suas instâncias e esferas. Um exemplo claro disso é narrado por Robert McKee em seu livro sobre roteiro cinematográfico (2004) no qual relata que o número de roteiros registrados no Writers Guild of America - o sindicato dos roteiristas norte-americanos - chega a trinta e cinco mil ao ano, porém apenas um 
"punhado" desses roteiros chega a ser selecionado pelos estúdios, e um número bem reduzido é realmente produzido. A razão deste filtro se dá exatamente pelos riscos envolvidos em todos os elos dessa cadeia produtiva que é movida por uma tendência a prever o gosto do público, isto é, tais estúdios tentam antever a probabilidade de um filme fazer sucesso, seja para um grande público como o gerado pelos blockbusters com suas quebras de recorde de arrecadação, seja para um público segmentado como o gerado pelos filmes alternativos - ditos cult - que ao menos pagam o dinheiro investido e rendem dividendos respeitáveis (leia-se indicações em festivais ou Oscar).

Entretanto, por ser uma ciência pouco exata esta, a de prever o gosto do público, é que o mercado acaba se escorando em fórmulas já testadas por outros filmes, como o próprio Mckee esclarece (ibid.: 68-70), o que gera uma padronização da filmografia, e, consequentemente, do gosto do público. De fato, o desenvolvimento de tal padronização sufoca a diversidade e acarreta o empobrecimento de todo um contexto sociocultural (ver MORIN, 2008, p. 148). Isso acontece não só no cinema de indústria, mas também pode ocorrer nos cinemas ditos nacionais que às vezes embarcam em uma ideia de identidade e/ou representatividade unidirecional. Assim, com o intuito de se explorar um caráter exótico ou peculiar de uma determinada cultura, sociedade ou geografia, tais cinemas concentram-se em abordar um diferencial específico em relação a outras cinematografias. O problema não consiste em apresentar o diferencial, mas padronizá-lo e simplificá-lo como único possível.

Embora os fatores de risco em uma produção cinematográfica possam ser inúmeros e múltiplos, ainda assim, é sabido que se produzem muitos filmes ao ano, seja na América do Norte, na Ásia, na África, na Oceania, na Europa ou na América Latina. Portanto, imaginar que a proporção dos filmes não realizados, os chamados "engavetados", seja muito maior que os realizados é pensar que, dentro desse processo poético - industrial e/ou autoral -, existe muita agitação inútil, despesas vãs, energia dilapidada e um tanto de hemorragias dispersivas (MORIN, 2008, p. 112).

Foi logo nas primeiras décadas após o surgimento do cinema, que os norte-americanos, para se estabelecer como indústria, adotaram como modelo criativo-produtivo a lógica das fábricas que na época tinham como paradigma o fordismo-taylorismo. A máxima desse sistema era a busca de uma eficiência produtiva atrelada a uma maior rentabilidade, lucro. Apesar de existirem outros modos de produção cinematográfica principalmente na Europa, vinculados ou aos moldes das companhias de teatro, ou às escolas fomentadas pelo Estado, ou aos

Revista Digital do LAV - Santa Maria - vol. 10, n. 1, p. 14 - 30 - jan./abril. 2017 ISSN 1983 7348 http://dx.doi.org/10.5902/1983734823914 
moldes do artista em seu atelier, é o modelo norte-americano de produção de massa que acaba se tornando hegemônico, principalmente ao final da Segunda Guerra Mundial (1939-1945).

Neste tipo de sistema mecanicista, o especialista é responsável por apenas uma parcela do processo e muitas vezes ignora o todo. Como uma máquina, este "profissional" executa um "programa" específico e sua atuação 'criativa' é subestimada e reduzida a uma mera formalidade já pré-formatada. Seu envolvimento com o todo é bem limitado e restrito imperando sobretudo uma hierarquia verticalizada que domina suas ações. Não existe, portanto, uma autoria propriamente dita, e quem "assina" é a empresa/estúdio e o produtor responsável pela execução da empreitada/obra.

É ao final da década de 1950 e começo de 1960, na França, que se inicia um movimento contrário a este tipo de cinema impessoal/industrial/capitalista. As reflexões sobre um "novo cinema" são feitas por meio do Cahiers du Cinèma revista que tem como um de seus idealizadores André Bazin - e, o filme, feito com a câmera stylo, termo cunhado por Alexandre Astruc em 1948, recebe o nome de Nouvelle Vague. Truffaut, Godard, Rivette, Chabrol e Resnais fazem coro ao conceito romântico da câmera caneta e advogam a favor de seu aspecto mais autoral, defendendo que o novo cinema deveria ter o toque e o estilo do diretor. Assim, o filme deveria conter uma identificação entre obra e autor, uma semelhança entre ambos. Dessa forma, o diretor impregna o filme com sua personalidade, imprime sua assinatura, algo já discutido anteriormente por S. M. Eisenstein e Jean Epstein ainda nas décadas de 1920 e 1930, mas que volta com fôlego renovado diante de um contexto avesso ao capitalismo e à indústria cultural. Nas discussões trazidas ao Cahiers são eleitos os diretores que possuem esse toque autoral em suas obras, alguns inclusive do mainstream hollywoodiano como Hitchcock, Minelli e Hawks.

A partir desse momento, o diretor de cinema, antes um técnico responsável por conduzir um empreendimento lucrativo dentro de uma indústria cultural muito bem estabelecida e articulada, é promovido a "arauto da verdade" cujo papel era o de denunciar os mecanismos por trás do status quo burguês. $\mathrm{O}$ resgate do culto ao autor foi uma medida emergencial dentro de um contexto específico, mas que acabou fomentando o surgimento de "Novos Cinemas" nacionais e/ou autorais em diversos países, muitas vezes contrários ao imperialismo cultural norte-americano. Entretanto, o primeiro a alertar sobre esse caráter mítico/religioso em torno do diretor de cinema foi o próprio André Bazin no Cahiers ao escrever que não se poderia colocar os diretores como 
personalidades infalíveis e perfeitas a serem veneradas em novos pedestais (ver STAM, ibid., p. 107).

Em defesa ao cinema de 'qualidade' sacralizado pelos norte-americanos, alguns críticos, como Andrew Sarris e Pauline Kael (ver STAM, ibid., p. 108-111) da revista nova-iorquina Film Culture, rebatem a forma como o diretor era visto na politique des auteurs francês, pois ao romanceá-lo na figura de um escritor gênio, os franceses ignoravam o fato de que o cinema era uma arte colaborativa. Assim, falar em autoria no cinema teria que passar pelo fato de que um filme, para ser produzido e distribuído, precisaria de financiamento, mercado, pessoal especializado e, claro, um diretor que conseguisse imprimir seu ponto-de-vista, sua marca e personalidade. De fato, as críticas mais assimilaram a politique do que desautorizaram a própria política dos estúdios norte-americanos tornando o culto aos cineastas um excelente chamariz publicitário similar ao realizado em relação aos atores e atrizes, chamados de "estrelas" e "astros" pela mídia especializada.

O autorismo francês conferiu aos cineastas norte-americanos um status que não tinham, permitindo, ao longo do tempo, uma certa autonomia criativa. Isso não quer dizer que os estúdios tenham deixado de interferir e até deturpar os filmes de muitos dos cineastas considerados 'geniais', ao contrário. Por outro lado, o cinema de autor, ou melhor dizendo, o culto ao autor, não deixou espaço a uma reflexão outrora lançada por Walter Benjamin em 1936 ao observar que o filme era uma criação da coletividade. Torna-se urgente complexificar essas posições antagônicas e complementares.

\section{Sobre Organização, Intercâmbios e Multiprocessos}

A realização de um filme implica a integração e interação de um conjunto de agentes especializados em áreas nas quais, em outras artes, aparecem como dominantes, mas que, no caso do cinema, são co-participantes. O que Riccioto Canudo havia previsto como o mito da arte total ao se referir ao cinema (STAM, 2003, p. 43) torna-se palpável nos sets de filmagem em que artistas de diferentes formações são unidos no desenvolvimento de uma obra complexa.

O fato de o cineasta tomar as decisões cruciais na realização do filme não tira a co-autoria dos outros agentes nem o caráter poético de suas funções no que tange à confecção do filme. Seguindo essa perspectiva, o que se constata é que essas interações (MORIN, 2008, p. 105) que compõem e moldam a 
realização de um filme configuram-se como sistêmicas, isto é, há um conjunto de agentes semióticos com funções específicas que interagem e se integram na realização da obra.

Esta interação entre agentes especializados e sua integração imersa à produção de um filme forma uma organização ativa - sistema - cuja matriz processual é forjada pelo jogo multiforme e relativo entre diversidade, variedade, antagonismo, desvio, ruptura, equilíbrio, ordem e desordem. Assim, uma visão holística simplificadora de que um filme seja um todo harmônico é aqui posta em xeque logo de início. Porque "(...) a ideia de sistema não é apenas harmonia, funcionalidade, síntese superior; ela traz em si, necessariamente, a dissonância, a oposição, o antagonismo" (MORIN, ibid., p. 154).

Assim, um filme não é assinado apenas por um autor, mas por um conjunto de autores, cujas especialidades complementam-se, coadunam-se e retroagem em um policircuito recursivo (MORIN, ibid., p. 231), cuja dinâmica opera em torno de concessões, cooperações e associações entre as competências participantes. De fato, essa unidade complexa do cinema depende de uma ecoorganização (MORIN, 2005, p. 35-42), cuja dimensão comporta uma natureza temporal, isto é, uma organização que se dá no tempo (VIEIRA, 2008, p. 93) e cuja lógica gira em torno de processos temporais, que por sua vez comportam transformações, flutuações e intersemioses.

o que se observa é que há, em graus maiores ou menores, o risco de essa combinação entre agentes e especialidades entrar em processo de entropia (MORIN, ibid., p. 94), perdendo a coesão sintática e a coerência semântica, prejudicando as interfaces e intercâmbios intersemióticos entre suas várias camadas de significação. Essas camadas de significação são cunhadas e entrelaçadas pela integralidade e organização da direção de fotografia, direção de arte, figurino, cenografia, trilha sonora, roteiro, direção etc., dentro de um todo complexo, o filme.

De fato, a riqueza organizacional de um sistema é medida pela sua diversidade e variedade, pois sua lógica é pautada pela transformação, geração e produção, ou como Morin destaca: as interações e associações - entre essas áreas distintas inerentes ao processo de realização cinematográfica - "se entreproduzem" (MORIN, ibid., p. 202).

Portanto, ao fim, a poética desenvolvida no cinema é confeccionada nesse jogo ontológico sistêmico das interações entre agentes semióticos responsáveis por comporem um todo múltiplo e cooperativo (MORIN, ibid., p. 147). Assim, cada agente, em sua especialidade, é responsável por um fragmento sígnico que 
passa pelo crivo de sua criação, desenvolvimento e produção. Esse fragmento tem que: a) conectar-se; b) traçar relações; c) estruturar-se, isto é, estabelecer e fortalecer essas relações intersemióticas - de troca - ao longo do período de realização fílmica; d) integrar-se a outras partes sígnicas em um processo de complementaridade; e) cumprir uma função, visando uma cooperação mútua e interdependente; f) e corporificar-se em uma organização (ou organicidade) coesa o suficiente que consiga desenvolver uma regularidade pragmática durante todo o processo de realização do filme. De fato, uma fotografia, um figurino, uma direção de arte, por exemplo, integram-se e tomam corpo pela complexidade com que dialogam entre si, pelas interfaces e intercâmbios sígnicos que são capazes de realizar e, principalmente, manter e entreproduzir, portanto, transformar (MORIN, ibid., p. 148).

O que faz essa multiplicidade de agentes funcionarem em uma unidade complexa e inter-atuante é aquilo que Aumont chama de ideia do filme, que o cineasta tem da obra ainda no início de seu processo criativo (AUMONT, 2006, p. 136). Nesse sentido, essa ideia coloca esses subsistemas em atividade formando um policircuito recursivo retroativo entre o todo às partes, e entre as partes ao todo. Isso quer dizer que as partes - subsistemas - retroagem recursivamente sobre o todo - o filme - e o todo, por sua vez, retroage recursivamente sobre as partes formando esse policircuito no qual as intersemioses, flutuações e transformações fazem morada (MORIN, ibid., p. 228).

De fato, essa ideia desencadeia os fluxos e os multiprocessos - círculoevoluções - entre os subsistemas e essa dialogia - entre roteiro, direção de arte, direção de fotografia, cenografia, figurino, atores, direção, montagem, trilha sonora etc. - ocorre em torno dessa ideia-chave. Essa nucleação em torno de uma ideia que move a organização é o fechamento do sistema, porém não é um fechamento total ao ambiente em que está imerso, pois a ideia nucleadora, para ter autonomia, alimenta-se de saberes - memória - aos quais essa ideia-chave está umbilicalmente conectada. Assim, a nucleação do sistema - o que implica dizer difusão de informação e a elaboração/execução de método/estratégia de performances - favorece o florescimento dos subsistemas, isto é, promove a diversidade (leia-se riqueza), provê a interdependência (leia-se complementaridades) e permite o intercâmbio (leia-se intersemioses) entre as partes e o todo neste policircuito recursivo retroativo.

Cada subsistema possui uma herança e uma memória que se torna, ao fim e ao cabo, fonte de saberes, competências e de conhecimento de articulação de linguagem (MORIN, ibid., p. 210). O roteiro, herança da literatura (AUMONT, ibid., 
p. 40) e da dramaturgia, serve de guia para a produção que se concentra em tentar trazer à superfície a história ali descrita, fazendo uma analogia, o roteiro seria a planta-baixa de um edifício que vai consumir horas e horas para ser erigido. A direção de arte (herança das artes plásticas) trata de esboçar e estabelecer os aspectos visuais sugeridos pelo roteiro e pelo diretor; o cenógrafo (herança do teatro e em alguns aspectos da arquitetura) trata de dar vida e relevo aos espaços onde a encenação será realizada; o figurinista (herança da moda e do teatro) trata de encarnar no vestuário os aspectos sociais, históricos e psicológicos dos personagens com intuito de dar dimensão a estes; o diretor de fotografia (herança da própria fotografia) trata de escrever a história ali encenada por meio da disposição e articulação das luzes, lentes e enquadramentos; o compositor da trilha sonora (herança da música) trata de contar e transmitir os sentimentos das cenas encenadas por meio da música. Ainda que inserida na pós-produção, a música tem o caráter de enaltecer e intensificar a encenação e a montagem; o diretor (herança das outras artes) é um autor complexo que possui a competência conjugada do regente, pintor, escritor, encenador, fotógrafo, arquiteto, poeta e compositor. É, sobretudo, um mediador de competências cujo discurso se desenvolve por meio da integração e consolidação de uma dialogia entre os outros agentes semióticos envolvidos no processo de criação do filme. Ele forja sua independência na e pela dependência dos especialistas envolvidos (ver MORIN, ibid., p. 253). Assim, sua poética é articulada por meio de uma ecodependência, e sua plenitude criativa floresce e ganha brilho ao permeá-la de colaborações, cooperações e complementações.

Morin define um subsistema da seguinte maneira: é "(...) todo sistema que manifeste subordinação em relação a um sistema no qual ele é integrado como parte" (MORIN, ibid., p. 175). Assim, cada subsistema como direção de arte, roteiro, direção de fotografia, trilha sonora, direção, cenografia, figurino, montagem, atuação etc., possui uma história - memória - que advém, de uma forma ou de outra, de artes pregressas ao cinema. Portanto, cada subsistema carrega consigo uma herança semiótica que passa por transformações no meio cinematográfico. Assim, se, por um lado, essas especialidades desenvolveram as potencialidades do cinema, por outro, o meio permitiu e propiciou novos desdobramentos e novas articulações às especialidades em um processo recursivo retroativo.

Entretanto, este circuito, formado por subsistemas cujas especialidades são postas para atuarem em conjunto, envolve um fator tempo que subjaz a todo o sistema. Assim, cada subsistema passa por fases evolutivas de maneira 
diferenciada e em momentos específicos durante a produção de um filme. Daí o termo círculo-evoluções, pois o fim de um processo é o começo de um outro. Ou como Morin define é um : "(...) multiprocesso retroativo se fechando em si mesmo a partir de múltiplos e diversos circuitos (...)" (MORIN, ibid., p. 231). Assim, o término do roteiro é o início da pré-produção, o fim da pré-produção é o início da produção ou filmagem, o fim deste último é o começo da montagem e da pós-produção, portanto é um policircuito retroativo recursivo, no qual os subsistemas evoluem por um processo criativo que contém fases distintas e momentos específicos como: rompimento, preparação, incubação, expansão ou iluminação, transição ou verificação, maturação ou formulação e clímax (ver VIEIRA, 2008, p. 58) ${ }^{1}$.

\section{Sobre visualidades, identidades e eterno aprendizes}

Uma área como a direção de arte e/ou design de produção - como os norte-americanos a distinguem - está intrinsecamente relacionada ao vasto campo da visualidade de sua identidade. De fato, sua herança semiótica inclui desde as primeiras representações imagéticas deixadas pelos homens das cavernas às intervenções atuais da linguagem digital na composição de imagem, sendo comum ao diretor de arte e/ou designer de produção atuar criando desde esboços com papel e lápis a concepts animados e virtuais via tecnologia 3D. Sua função é dar forma ao design visual de um filme, isto é, este profissional tem a responsabilidade de traduzir em imagens o conceito idealizado pelo diretor e exposto no roteiro por meio da linguagem verbal. Dessa maneira, a visão estética de um filme ganha seus primeiros contornos ao passar pela mente do designer.

A diferenciação entre designer de produção e diretor de arte no mercado norte-americano se deu com o filme $E$ o vento levou... (1939) produzido por David O. Selznick, dado o trabalho de William Cameron Menzies que detalhou com uma riqueza visual impressionante a composição das imagens - em desenhos e storyboards - a serem filmadas (ver RIZZO, 2005, p. 9). Levando em consideração o que Menzies havia realizado ao longo da produção, Selznick - ao dar os créditos a cada especialista envolvido - batizou de desenhista de produção o profissional responsável pela criação e desenvolvimento plástico de um filme diferenciando-o do diretor de arte, cuja função - dali em diante - seria o de

\footnotetext{
${ }^{1}$ Seguindo os passos de Jorge Vieira ao adaptar a proposta de Moles com as propostas evolutivas ontológicas de Mende - evolon - é possível compreender melhor em que momento ocorre os processos de abertura e fechamento - a cada subsistema - tão essenciais à nucleação na realização de um filme.
}

Revista Digital do LAV - Santa Maria - vol. 10, n. 1, p. 14 - 30 - jan./abril. 2017 ISSN 1983 7348 http://dx.doi.org/10.5902/1983734823914 
transformar os desenhos e as composições elaborados pelo designer em cenários, figurinos, objetos de cena etc. Entretanto, fora deste ambiente hollywoodiano, essa diferenciação é quase inexistente, pois o diretor de arte é o único mediador destas duas funções: composição plástica e construção visual.

Tudo o que aparece em um filme de ficção passa pelo seu crivo, isto é, cada detalhe do arranjo visual da imagem em movimento tem o seu toque. Por isso, este departamento é tão crucial ao diretor de cinema, pois se, por um lado, o roteiro desenvolve a informação dos caminhos da história a ser contada, por outro, é a direção de arte que dá relevo, dimensão, profundidade, contornos e identidade à informação. Assim, situar os aspectos e as características da representação visual a ser adotada em um filme é propiciar que este ideal estético buscado pelo cineasta se torne tangível. Portanto, o sentido de tatear a realidade almejada para o filme não seria distante do que o diretor de arte fornece e propõe aos outros subsistemas.

Mesmo em filmes mais "realistas" ou até em documentários, sua função ainda permanece atrelada ao fato de poder fornecer locações e ambientações correspondentes ao drama a ser retratado, flagrado ou representado. Isso consiste em dizer que certos filmes - com seus gêneros - dependem, em graus variados, deste profissional de maneira ou mais acentuada ou mais branda. $\mathrm{O}$ fato é que não se pode atribuir a este especialista a função apenas de construção de cenários e de confecção de vestuário dos personagens. Como Rizzo destaca (ibid., p. 16), tal profissional tem que ser versado em arquitetura, moda, história, psicologia, fotografia, design de interior, tecnologia, política, ecologia, economia etc., pois para construir, retratar, flagrar e desenvolver uma realidade ficcional ou não, em dimensão e relevo, todas as esferas de ação estão intimamente envolvidas e vinculadas.

Essa complexidade, em consonância à realidade que nos cerca, é divisada em pormenores no arranjo visual de um filme pela habilidade de um diretor de arte. Da mesma maneira, a realidade apresenta em sua visualidade uma rede de informações embutidas, amalgamadas e urdidas em várias esferas, desde sua história geológica, urbana até cosmológica. A realidade encontrada em um filme também apresenta ou simula essa rede de inter-relações, não em seu todo, mas no período de tempo e espaço a que se reporta. Assim, tudo o que aparece está recheado de informações que são transmitidas pelo arranjo e pela disposição visuais. Rizzo (ibid., p. 17) acrescenta que um diretor de arte habilita-se a ter a licença de ser um eterno aprendiz, pois a cada novo filme uma faceta da realidade ou um novo mundo é (re)criado e desenvolvido. Dessa forma, para que 
um filme adquira uma identidade visual, há necessidade de uma extensa pesquisa para se produzir a complexa rede de inter-relações transmitidas, não pelo diálogo entre os personagens ou por um narrador, mas, pelo design do filme.

Com o roteiro lido, e de posse das informações passadas pelo diretor, o diretor de arte começa - Rompimento - sua pesquisa iconográfica. Nessa fase de Preparação, este profissional expande ao máximo sua área de estudo em torno do ideal estético adotado ao filme. Seja frequentando bibliotecas, livrarias, museus, exposições, locações, ou buscando novos contatos, pesquisadores e peritos, ou ainda acessando jornais, revistas, internet, tal fase é marcada pelo crescimento e acúmulo de informações que permita a esse profissional fazer conexões de elementos a respeito do universo a ser representado.

Todavia, nem todo cineasta desenha como um Fellini ou Kurosawa, o que auxiliaria o diretor de arte a compreender o que o diretor tem em mente, por isso boa parte dos diretores utiliza-se de referências visuais diversas - pintura, fotografia e filmes, por exemplo - para traçar um direcionamento. Ainda que se busque uma identidade original ao filme, tais referências auxiliam o diretor de arte a se arvorar no caminho certo e não trilhar a esmo, o que consumiria energia, tempo e recursos em um ambiente em que desperdício significa estouro de orçamento e paralisação da produção.

Rizzo (ibid.: p. 53-59) destaca que essa fase de pesquisa demanda uma ferramenta de arquivamento de dados - um computador ou um servidor - que permita ao diretor de arte armazenar todo esse material a que teve acesso, de modo a organizá-lo de maneira a facilmente acessá-lo, quando necessário. Durante esse período, o escritório ou ateliê de um diretor de arte - em meio a uma pré-produção - é forrado de imagens de origens diversas, paleta de cores, trapos de tecidos, amostras de materiais e outros objetos afins ao longo de suas paredes e móveis, além de um computador abastecido com uma multiplicidade de informações. De maneira diagramática, uma rede de interconexões é criada, em consonância às descrições do roteiro e às preleções do diretor.

Essas referências vão Ihe fornecer a base para a segunda fase - Expansão ou Incubação - que envolve a criação e desenvolvimento dos desenhos, ilustrações e concepts visuais referentes aos personagens e aos ambientes sugeridos pelo roteiro. Nesse período, ocorre a elaboração de storyboards - que consiste na visualização das ações em detalhes similar ao encadeamento narrativo encontrado em uma história em quadrinhos e que serve de base para a comunicação entre o diretor de arte e o diretor de fotografia e com o diretor - e dos animatics - que possuem o mesmo princípio do storyboard. Entretanto, a 
ação visual é desenvolvida em uma interface 3D, sem muito detalhamento, porém, em movimento. É possível, também, dependendo da produção, encontrar nessa fase a construção de maquetes dos cenários e ambientes que, se aprovados, serão erguidos em tamanho real. Entretanto, em alguns casos, essas maquetes podem ser desenvolvidas via softwares que utilizem tecnologia 3D fartamente utilizada em projetos arquitetônicos na construção civil. Outra possibilidade é o uso de fotografias das locações, como substituto aos tradicionais desenhos feitos a mão ou storyboards e que serão posteriormente tratadas via interface digital, com o intuito de se expor as nuances, as cores e os matizes com que esse profissional trabalhará ao longo do filme.

De fato, na segunda fase, chamada de Expansão, a rede de interconexões, articulada na fase de pesquisa, ou Preparação, dá contornos mais detalhados das possibilidades visuais em torno do projeto. Uma diversidade impressionante de esboços, imagens e objetos são criados, portanto, é a fase marcadamente abdutiva/hipotética do diretor de arte cujo pensamento desenvolve-se pelo jogo variável das formas.

A informação, que anteriormente foi desenvolvida e articulada pela linguagem verbal via roteiro, agora transcorre (leia-se semiose) por uma outra tradução: a visual. O que era uma descrição de ambiente transforma-se em uma maquete virtual, cujo espaço é dimensionado. O que era um detalhe sugerido sobre um vestuário transforma-se em uma ilustração que serve de base para visualizar-se um personagem. O que era uma ação exposta no roteiro em espaços paralelos torna-se um animatic que permite observar e antever o transcurso da narrativa e a maneira de se disporem os posicionamentos de câmera. É essa plasticidade da imagem que é urdida, forjada e criada ao longo dessa fase de Preparação.

A fase seguinte, a Transição ou Iluminação, é marcada pela restrição das fronteiras. Se, na fase de Expansão, o processo de elucubração de hipóteses é que dá a tônica desse período, na fase de Transição, o diretor de arte tem seus limites restringidos não só ao roteiro, mas às escolhas, às decisões e às sugestões do diretor, ao orçamento e ao raio de ação ou campo de visão da câmera. Aliás, é para as lentes da câmera que este design visual é composto (ver RIZZO, ibid., p. 78-85). Nessa fase, marcada pelo pensamento dedutivo, é que as primeiras propostas visuais são apresentadas. Desde esboços, ilustrações, fotografias até alguns storyboards são apresentados ao diretor que vai aparando as arestas, descartando, escolhendo e indicando ao diretor de arte o que the convém aos efeitos e resultados que almeja alcançar.

Revista Digital do LAV - Santa Maria - vol. 10, n. 1, p. 14 - 30 - jan./abril. 2017 ISSN 1983 7348 http://dx.doi.org/10.5902/1983734823914 
Assim, o excesso de possibilidades visuais encontradas na fase de Expansão sofre rearranjos, reordenamentos e realinhamentos nesta fase de Transição. O diretor de arte sabe que isso é um processo natural, porém não hesita em apresentar ao diretor suas ideias, propostas e hipóteses em excesso. Aliás, o diretor espera isso dele, pois certas pesquisas visuais, realizadas pelo diretor de arte, às quais o cineasta não teve acesso, podem ser decisivas na escolha de uma locação, de figurino, de objeto de cena ou cenário. Portanto, a fase de Transição marca a fixação dos limites da produção, isto é, o momento em que se tomam as decisões cruciais que irão envolver a maioria dos outros subsistemas, uma vez que, por exemplo, ao decidir sobre um vestuário de um personagem a partir de um concept, o figurinista é acionado e começa a desenvolver seu trabalho, ou, ao decidir pela construção de um cenário, o cenógrafo inicia seu trabalho a partir da ilustração aprovada.

De fato, de posse das escolhas realizadas na fase de Transição e ainda mais alinhado aos anseios do diretor, o diretor de arte não trabalha mais com possibilidades ou esboços, e sim com o material visto e aprovado, portanto, fixo. Deste ponto em diante, esse profissional aciona, transmite, delega - a seus assistentes e aos responsáveis pelos outros subsistemas que estiverem vinculados ao departamento de arte - o design visual escolhido para cada setor e que agora mobilizará os respectivos especialistas.

A fase seguinte, de Maturação ou Verificação, é marcada por um gerenciamento dos subsistemas atrelados à direção de arte - como cenografia, figuração, maquiagem, efeitos especiais etc. - com o intuito de se observarem os resultados de cada setor (ver RIZZO, ibid., p. 137-186). Nesse período, marcado pelo pensamento indutivo, ocorrem os testes de figurino, de certificações na construção de cenários e/ou na adaptação das locações, de verificações dos efeitos visuais, mecânicos ou de maquiagem. Portanto, o diretor de arte coordena de perto e revê cada detalhe, pois tudo o que outrora fazia parte de suas ilustrações e imagens de referência, agora, toma corpo, relevo e dimensão em escala real. Tudo o que era um ideal estético concretiza-se e é testado.

Ao passar por essa fase de Maturação, que consiste em aprimorar e afinar o visual dos elementos cênicos do filme, a pré-produção cessa, e começa uma nova círculo-evolução: a filmagem. A fase de Clímax da direção de arte floresce exatamente durante o processo de filmagem, pois todo o trabalho de criação, desenvolvimento e gerenciamento - inclusive de orçamento - aparece consolidado a cada set, a cada tomada, a cada ação filmada. Há uma interação dialógica entre os subsistemas, - maquiagem, figurino, cenários, locações, efeitos 
visuais, efeitos mecânicos - e são essas intersemioses promovidas por esses arranjos - sintaxe - que formam o design plástico do filme. Portanto, é quando esta integralidade efetua-se nos sets que o subsistema regido pela direção de arte encontra seu ápice.

$\mathrm{Na}$ verdade, a presença do diretor de arte nos sets de filmagem - com seu olhar clínico e detalhista - ajuda o diretor a concentrar-se com melhor acuidade nas interações dos movimentos e das ações diante da câmera, pois, em alguns casos, certas nuances, ou mesmo problemas que poderiam passar desapercebidos pela maioria, podem ser identificados e rapidamente solucionados pelo diretor de arte seja no figurino, na maquiagem, no cenário e assim por diante.

Muito embora o diretor de arte seja uma presença fundamental nas fases de pré-produção e produção, é comum atualmente vê-lo na fase de pós-produção em contato direto com o supervisor da equipe de efeitos digitais, já que suas ilustrações servem de base para o desenvolvimento de cenários e personagens virtuais, ou no tratamento, coloração e estilização das imagens capturadas na fase de filmagem. Assim, em conformidade ao avanço dos softwares que lidam com a criação, desenvolvimento e tratamento de imagens em movimento, sua função como designer ao longo da realização fílmica tem-se arvorado e estendido para a fase de pós-produção, em razão de esta lidar diretamente com a consolidação (leia-se fechamento) visual do filme.

\section{Considerações Finais}

A direção de cinema implica não uma especialização, mas uma polifuncionalidade (MORIN, 2005, p. 346), isto é, uma visão multifacetada das interrelações integrantes e copulantes nas e pelas quais a poética do cinema está imersa. Ele é um autor que não só tem que olhar para seu processo criativo, mas também compreender o mercado, as formas de financiamento e a maneira como vai empreender sua carreira/estilo.

O diretor de arte tem um papel fundamental nesse processo de consolidação de uma carreira/estilo, pois este é co-autor dessa poética cinemática. Ambos comungam de uma mesma ambição criativa e de carreira. Tal vínculo, entre cineasta e diretor de arte, é estabelecido no momento em que percebem que o filme/obra torna-se algo maior exatamente pelo viés das associações, colaborações e ajustes mútuos na performance de ambos, e também com outros integrantes da equipe criativa, são, portanto, ecodependentes. Esse 
ambiente traz-Ihes autonomia tanto criativa em relação ao(s) filme(s) como em relação a própria vida profissional em projetos futuros.

Essa ação ecológica em que cada integrante influi sobre o trabalho criativo do outro em um dialogia ecodependente nos alerta ao fato que a produção dos signos no cinema não ocorre de forma isolada, ao contrário, ela é complexa e sistêmica. Assim, quando esse processo colaborativo surge e evolui de maneira positiva, é uma via de mão dupla pautada por uma empatia que se renova, retroage, permeia e aflora ao longo das fases de pré-produção, produção/filmagem e pós-produção. Essa empatia permite que as competências entrem em um fluxo de complementaridade, isto é, em uma sinergia de sentido. Dessa forma, a verticalidade hierarquizada cede espaço a uma horizontalidade cooperativa.

Entretanto, tal ambiente de trabalho não é algo simples de se encontrar ou promover, pois depende que todas as partes exercecitem: tolerâncias, partilhas, concessões e afinidades. Algo que a visão mecanicista fordistataylorista ignora e a visão romântica de autor esvazia. É por isso que quando um diretor 'encontra' uma equipe cujos integrantes partilham de uma mesma sinergia, esta permanece com o cineasta ao longo de sua carreira e/ou por muitos filmes, pois é a equipe que permite que 'sua-deles-deles-sua' poética se consolide.

\section{Referências:}

ARISTÓTELES. (2005) Arte Poética. São Paulo: Martin Claret Editora.

AUMONT, JACQUES. (2004) As teorias dos cineastas. Campinas: Papirus Editora. (2006) O cinema e a encenação. Lisboa: Edições Texto \& Grafia.

AUMONT, Jacques e outros. (2002) A estética do filme. Campinas: Papirus Editora.

BENJAMIN, Walter (1996). Obras escolhidas I - Magia e técnica. Arte e política. São Paulo: Editora Brasiliense.

BORDWELL, David. (2008) Poetics of Cinema. New York: Routledege.

MCKEE, Robert (2004). Story - Substância, estrutura, estilo e os princípios da escrita de roteiros. Curitiba: Arte \& Letra Editora.

Revista Digital do LAV - Santa Maria - vol. 10, n. 1, p. 14 - 30 - jan./abril. 2017 ISSN 1983 7348 http://dx.doi.org/10.5902/1983734823914 
MORIN, Edgar. (2008) O Método 1 - a natureza da natureza. Porto Alegre: Editora Sulina.

(2005) O Método 2 - a vida da vida. Porto Alegre: Editora Sulina.

PEIRCE, Charles S. (2000) Semiótica. São Paulo: Editora Perspectiva.

(1998) Antologia Filosófica. Imprensa Nacional - Casa da Moeda, Portugal.

(1992) The Essential Peirce - Volume 1. Bloomington:

Indiana University Press.

(1998) The Essential Peirce - Volume 2. Bloomington:

Indiana University Press.

RIZZO, Michael. (2005) The Art Direction handbook for film. Burlington: Focal Press.

SANTAELlA, Lucia. (2000) Estética - de Platão a Peirce. São Paulo: Editora Experimento.

STAM, Robert. (2000) Introdução à teoria do cinema. Campinas: Papirus Editora.

VIEIRA, Jorge de Albuquerque. (2007) Ciência - Formas de Conhecimento: Arte e Ciência uma visão a partir da complexidade. Fortaleza: Gráfica e Editora.

(2008) Ontologia - Formas de Conhecimento:

Arte e Ciência uma visão a partir da complexidade. Fortaleza: Expressão Gráfica e Editora.

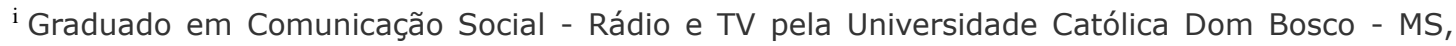
Especialista em Comunicação Audiovisual pela PUC-PR, Mestre e Doutor em Comunicação e Semiótica pela PUC-SP, Pós-Doutorando pela Universidade do Algarve, Portugal, atuando principalmente nos seguintes temas: Poética do Cinema, Autoria Colaborativa no Cinema, Montagem, Cinematografia, Interpretação Fílmica e Poética Transmidiática. É membro pesquisador do Centro Internacional de Estudos Peircianos - CIEP desde 2007.
}

Enviado em: 9 de novembro de 2016.

Aprovado em: 3 de março de 2017

Revista Digital do LAV - Santa Maria - vol. 10, n. 1, p. 14 - 30 - jan./abril. 2017 ISSN 1983 7348 http://dx.doi.org/10.5902/1983734823914 